\title{
Torque Ripple Reduction of a PM Synchronous Motor for Electric Power Steering using a Low Resolution Position Sensor
}

\author{
Kwan-Yuhl Cho ${ }^{\dagger}$, Yong-Kyun Lee*, Hyungsoo Mok*, Hag-Wone Kim**, Byoung-Ho Jun***, and Younghoon Cho \\ $\dagger^{* *}$ Dept. of Control and Instrumentation Engineering, Chungju National University, Chungju, Korea \\ ${ }^{*}$ Dept. of Electrical Engineering, Konkuk University, Seoul, Korea \\ ${ }^{* * *}$ Chassis Electronic Engineering Team, Hyundai-Mobis, Yongin, Korea \\ $¥$ Dept. of Electrical and Computer Engineering, Virginia Tech., Virginia, USA
}

\begin{abstract}
MDPS (motor driven power steering) systems have been widely used in vehicles due to their improved fuel efficiency and steering performance when compared to conventional hydraulic steering. However, the reduction of torque ripples and material cost are important issues. A low resolution position sensor for MDPS is one of the candidates for reducing the material costs. However, it may increases the torque ripple due to the current harmonics caused by low resolution encoder signals. In this paper, the torque ripple caused by the quantized rotor position of the low resolution encoder is analyzed. To reduce the torque ripples caused by the quantization of the encoder signals, the rotor position and the speed are estimated by measuring the frequency of the encoder signals. In addition, the compensating $q$-axis current is added to the current command so that the $6^{\text {th }}$ order torque harmonic is attenuated. The reduction of torque ripples by applying the estimated rotor position and the compensated $q$-axis current is verified through experimental results.
\end{abstract}

Key Words: PM synchronous motor, Power steering, Rotor position estimation, Torque ripple

\section{INTRODUCTION}

In recent years, energy savings in vehicles has become an important issue worldwide. As a result, electric vehicles and hybrid electric vehicles, which are driven by electric motors, are being launched in the marketplace. In addition, some hydraulically controlled mechanical systems have been replaced by electric driven systems, such as power steering and braking systems. It is noted that MDPS systems have been applied to vehicles for several years due to their merits in fuel efficiency, steering performance, environment friendliness, and down-sizing due to the reduced number of components when compared to conventional hydraulic power steering [1]-[3].

MDPS systems can be classified into three types based on the electric motor's location. These types include column fitted, pinion fitted, and rack fitted. In small and medium sized vehicles, column fitted MDPS systems, as shown in Fig. 1, where the electric motor is mounted on the column are widely

Manuscript received Jul. 19, 2010; revised Aug. 9, 2010

$\dagger$ Corresponding Author: kycho@cjnu.ac.kr

Tel: +82-43-841-5329, Fax: +82-43-841-5320, Chungju Nat'1 Univ.

* Dept. of Electrical Engineering, Konkuk University, Seoul, Korea

** Dept. of Control and Instrumentation Engineering, Chungju National University, Chungju, Korea

*** Chassis Electronic Engineering Team, Hyundai-Mobis, Yongin, Korea

\$Dept. of Electrical and Computer Engineering, Virginia Tech., Virginia, USA

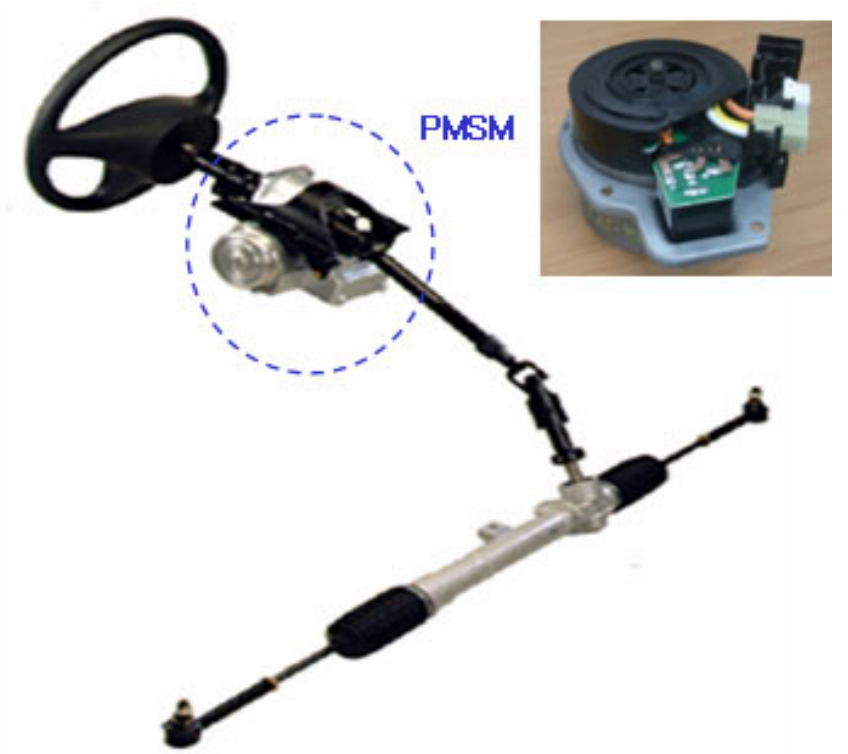

Fig. 1. Column fitted MDPS system.

used [1].

To drive the MDPS system, a permanent magnet DC Motor had been used due to its low torque ripple and its ease of torque control. Despite these advantages they have disadvantages such 
as the low efficiency, a slow dynamic response due to a large moment of inertia, and a short lifetime due to mechanical commutation by the commutator and the brushes.

Nowadays permanent magnet DC motors have been replaced by PM (permanent magnet) synchronous motors since they have advantages such as high efficiency, a long lifetime, a small moment of inertia, and excellent heat radiation when compared to permanent magnet DC motors [3]-[7]. PM synchronous motors in MDPS systems, however, have certain disadvantages such as noise and mechanical vibrations as well as the material cost for an extra inverter drive circuit [8]. The noise and vibration are mainly generated by the torque ripples of the motor, therefore, reducing the torque ripples is essential [9]-[13]. The torque ripples are generated by combined features such as a mechanical unbalance, magnetic saturation in the stator and the rotor cores, cogging torque, etc.

Torque ripples can be reduced by two approaches. The first approach is based on the motor structure while the second is based on the motor controller. For motor structure based torque ripple reduction, mathematical modeling to compute and reduce the cogging torque by a skewed rotor and a modified rotor structure was presented in [11], [12]. For control based torque ripple reduction, compensating currents that cancel out particular torque harmonics are added to the current command, where the compensating current is derived from a nonlinear analysis of the magnet saturation [13]. To apply the high frequency compensating current as well as the sinusoidal currents to a PM synchronous motor, precise information on the rotor position is required, through a resolver or an absolute encoder. These sensors, however, are too expensive and bulky to be used in compact MDPS systems. Although sensorless control without rotor position sensors may be applied, a physical sensor is still required due to the stringent safety and reliability requirements of a MDPS system [14].

Therefore, low cost rotor position sensors consisting of a magnet wheel, hall effect sensors, and an incremental encoder are commonly used in MDPS systems. The absolute rotor position is detected by combining the absolute rotor position with 60 electrical degrees obtained from hall effect sensors, with the high resolution encoder position obtained from an incremental encoder. The incremental encoder has a high resolution rotor position with 2048PPR (pulse per revolution), but it still has cost problems due to the encoder drive IC. In this paper, the encoder drive IC is replaced by low cost hall effect sensors to reduce the material cost, but the resolution of the incremental encoder is reduced to 64PPR.

In this paper, torque ripple reduction using the a low resolution incremental encoder is presented. The effect of the incremental encoder's resolution on the torque ripple is analyzed. The rotor position is estimated from the low resolution encoder signals. To reduce the torque ripple caused by mechanical unbalance, magnetic saturation, and cogging torque, an extra $q$-axis harmonic current is added to the reference current. The performance of the proposed torque ripple reduction based on an estimated rotor position is verified through experimental results.

\section{TORQUE RIPPLE ANALYSIS}

\section{A. Modeling of a PM synchronous motor}

In MDPS systems, the steering wheel torque is measured by a torque sensor when the driver manipulates the steering wheel. The input torque signal is transferred to the ECU (electronics control unit) which controls the motor torque. Depending on the input torque, the ECU generates a torque command to the motor to generate steering force, and then the motor generates the required torque.

The voltage equation of a surface mounted PM synchronous motor (SPMSM) in the $a b c$ frame can be given as:

$$
v_{a b c}=r_{s} i_{a b c}+\frac{d}{d t} \lambda_{a b c}=r_{s} i_{a b c}+L_{s} \frac{d}{d t} i_{a b c}+e_{a b c}
$$

where, $v_{a b c}$ and $i_{a b c}$ are the stator voltages and the stator currents, respectively, $e_{a b c}$ is the back emf induced into the stator windings, and $r_{s}$ and $L_{s}$ denote the phase resistance and the phase inductance, respectively. The $a b c$ frame voltage equation can be transformed to a $d q$-axis voltage equation in the rotor reference frame as shown in (2).

$$
\begin{aligned}
& v_{d}=r_{s} i_{d}+L_{d} \frac{d}{d t} i_{d}-\omega_{r} L_{q} i_{q} \\
& v_{q}=r_{s} i_{q}+L_{q} \frac{d}{d t} i_{q}+\omega_{r} L_{d} i_{d}+\phi_{f} \omega_{r}
\end{aligned}
$$

where, $\phi_{f}$ is the magnet flux, $\omega_{r}$ is the electrical angular velocity of the rotor, $v_{d}$ and $v_{q}$ are the $d$-axis and the $q$-axis voltages, $L_{d}$ and $L_{q}$ are the $d$-axis and the $q$-axis inductances, and $i_{d}$ and $i_{q}$ are the $d$-axis and the $q$-axis currents, respectively. The phase inductances in a SPMSM are almost constant so that the $d$-axis inductance and the $q$-axis inductance can be considered as equal.

The mechanical dynamics of a motor depends on the generated torque, the rotor inertia, the friction, and the load torque so that the torque equation for a SPMSM can be expressed as:

$$
\begin{gathered}
T_{e}=\frac{3}{2} \cdot \frac{P}{2}\left(\phi_{f} i_{q}+\left(L_{d}-L_{q}\right) i_{d} i_{q}\right)=\frac{3 P}{4} \phi_{f} i_{q} \\
=J\left(\frac{2}{p}\right) \frac{d}{d t} \omega_{r}+B\left(\frac{2}{p}\right) \omega_{r}+T_{f}+T_{c}+T_{L}
\end{gathered}
$$

where, $P$ is the number of poles, $J$ is the momentum of the inertia, $B$ is the coefficient of the viscous friction, and $T_{f}, T_{c}$ and $T_{L}$ denote the friction, the cogging torque, and the load torque, respectively.

\section{B. Analysis of torque ripples}

The encoder signals are quantized by the number of encoder pulses per revolution so that the rotor position of a low resolution encoder has quantized rotor position errors when compared to the actual rotor position. The quantized rotor position errors cause a distortion in the phase currents and they also generate torque ripples in the PM synchronous motor. The motor currents are controlled based on the quantized encoder signals, therefore, the $d q$ axis of the controller can lead or lag the actual $d q$ axis based on the actual rotor position. Fig. 2 shows the current vector and its projection to the $d r$-qr axis and the de-qe axis.

In Fig. 2, the $d r-q r$ axis is based on the actual rotor position with a high resolution and the $d e-q e$ axis can be considered as an imaginary axis based on the encoder's rotor position. 


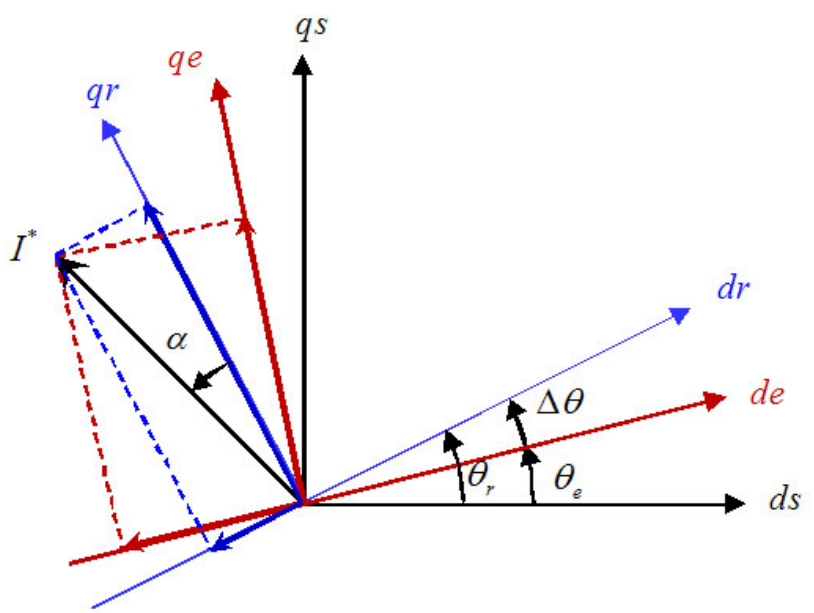

Fig. 2. Current vector and two $d q$ axes based on the actual rotor position and encoder rotor position.

The angle difference $\Delta \theta$ in Fig. 2 denotes the position error between the actual rotor position $\theta_{r}$ and the encoder rotor position $\theta_{\text {enc }}$

Assume that the current vector leads the back emf vector by an angle $\alpha$, then the $d q$ currents in the $d r-q r$ frame and the de-qe frame can be given by (4) and (5), respectively.

$$
\begin{gathered}
i_{d r}=-I^{*} \sin \alpha \\
i_{q r}=I^{*} \cos \alpha \\
i_{d e}=i_{d r} \cos \Delta \theta-i_{q r} \sin \Delta \theta=-I^{*} \sin (\alpha+\Delta \theta) \\
i_{q e}=i_{d r} \sin \Delta \theta+i_{q r} \cos \Delta \theta=I^{*} \cos (\alpha+\Delta \theta) .
\end{gathered}
$$

In MDPS systems, the torque ripple is serious in the low speed operating regions because the motor has low pass filter characteristics. In the high speed operating regions the torque ripples are attenuated by the motor. In the low speed operating regions in a surface mounted PM synchronous motor, the $q$ axis current controls the motor torque and the $d$-axis current is controlled to be zero to operate in the MTPA (maximum torque per ampere) mode. In the MTPA regions, the lead angle $\alpha$ in Fig. 2 is set to zero, therefore, the $d q$ currents in (4) and (5) can be given as follows:

$$
\begin{gathered}
i_{d r}=0 \\
i_{q r}=I^{*} \\
i_{d e}=-I^{*} \sin (\Delta \theta) \\
i_{q e}=I^{*} \cos (\Delta \theta) .
\end{gathered}
$$

It is noted that the rotor position difference between the actual rotor position and the encoder rotor position is small for a high PPR encoder since the resolution of the encoder signals is sufficiently high. For a low PPR encoder, on the other hand, the rotor position difference becomes large and it deteriorates the torque and the current control performance. The detected rotor position from encoder can be expressed as:

$$
\theta_{\text {enc }}=\frac{P}{2} 2 \pi \frac{n}{N_{\text {enc }}}=P \pi \frac{n}{N_{\text {enc }}} \text { for } 0 \leq n \leq N_{\text {enc }}-1
$$

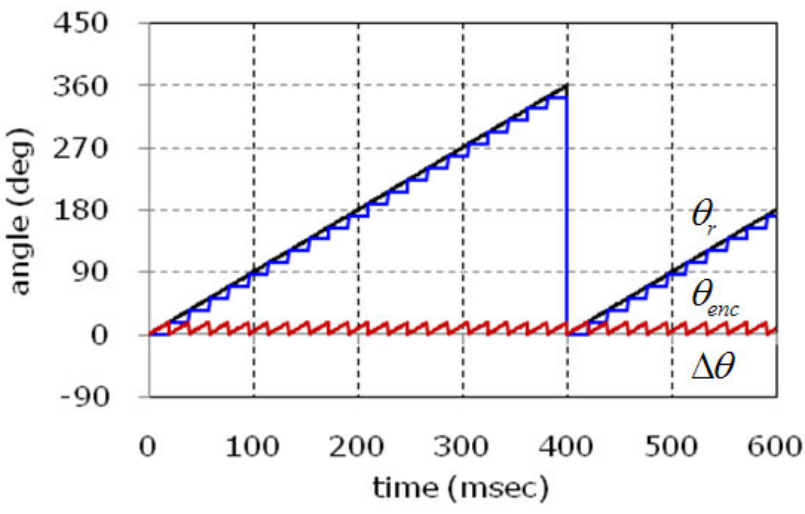

Fig. 3. Actual rotor position and quantized encoder rotor position.

where, $P$ is the number of poles, $N_{\text {enc }}$ is the number of encoder pulses per mechanical revolution, and $n$ denotes the index of the encoder pulses, ranging in numbers from 0 to $N_{\text {enc }}-1$.

Fig. 3 shows the actual rotor position and the detected rotor position from an encoder with 64PPR (pulse per revolution). The position error in Fig. 3 is caused by the quantization of the encoder signals. If we define the position error to be between the actual rotor position and the detected rotor position from the encoder as $\Delta \theta=\theta_{r}-\theta_{\text {enc }}$, then the maximum rotor position error due to the encoder signal's quantization may be given as follows:

$$
\Delta \theta_{\max }=P \pi \frac{1}{N_{e n c}} .
$$

From (7), it is noted that when the detected rotor position has a position error $\Delta \theta$ from the actual rotor position, then the generated torque decreases due to a decrease in the $q$ axis current. From (3), (6), (7), and (9), the torque differences between the torques controlled by the actual rotor position and the encoder signal can be derived as (10).

$$
\Delta T=T_{e}-T_{e n c}=\frac{3}{4} \phi_{f} I^{*}(1-\cos \Delta \theta) .
$$

The position error $\Delta \theta$ in (10) repeats saw-tooth waveforms during every cycle of the encoder pulses as shown in Fig. 3 so that the torque difference has similar waveforms. In this case, the maximum torque difference can be derived as (11) from (9) and (10).

$$
\Delta T_{\max }=\frac{3}{4} \phi_{f} I^{*}\left(1-\cos \Delta \theta_{\max }\right) .
$$

The torque difference given in (11) refers to the torque ripple generated by the quantized rotor position, so that the performance index of the torque ripple for the encoder signals can be defined as follows:

$$
\eta(\%)=\frac{\Delta T_{\max }}{T_{e}} \times 100=100 \times\left(1-\cos \left(\frac{P \pi}{N_{e n c}}\right)\right) .
$$

Fig. 4 shows the performance index of the torque ripples according to the number of encoder pulses for a 6 pole PM synchronous motor. The torque ripples above 500PPR are lower than $0.1 \%$, but the torque ripples below the 200PPR region increases exponentially as the number of encoder 


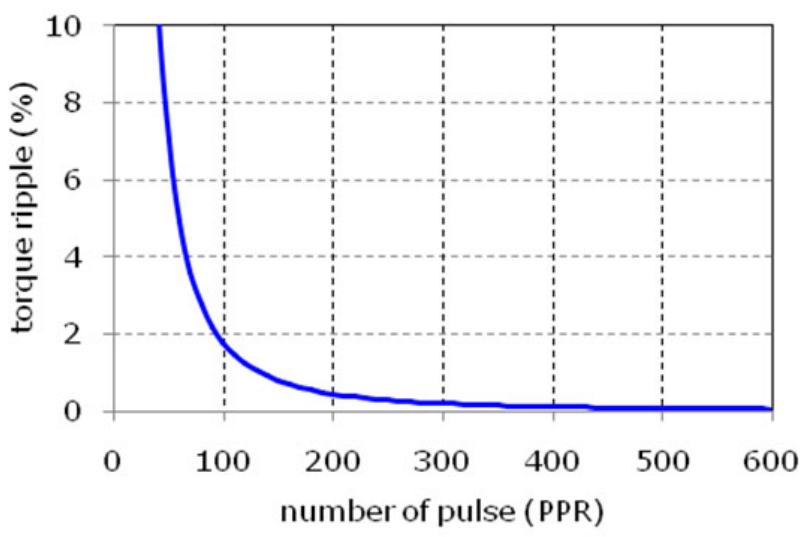

Fig. 4. Relationships between torque ripples and number of encoder pulses.

signals decreases. The torque ripple for a 200PPR encoder is $0.44 \%$, but it increases to $4.3 \%$ at $64 \mathrm{PPR}$, by only the quantization of the encoder signals. In real systems, the torque ripples may be larger than in the analysis because of the mechanical unbalance of the motor, the magnetic saturation in the stator and the rotor cores, the cogging, the friction torques, and the control performance including the current and the voltage control. Therefore, it is important to reduce the quantization errors of the encoder signals, especially for low PPR encoders.

\section{TORQUE RIPPLE REDUCTION WITH ROTOR POSITION ESTIMATION}

\section{A. Rotor position estimation}

The surface mounted PM synchronous motor used in this paper has 3 phases and 6 poles. The absolute rotor position is detected by combining the absolute rotor position with 60 electrical degrees from the hall effect sensors, with the low resolution incremental encoder position obtained from the hall effect sensors. In a conventional MDPS system, a high resolution encoder with 2048PPR was applied, therefore, the resolution of the rotor position was $0.176 \mathrm{deg}$ in mechanical angle and $0.527 \mathrm{deg}$ in electrical angle. The low resolution encoder used in this paper has 64PPR so that the resolution of the mechanical angle is $5.625 \mathrm{deg}$, that is, $16.875 \mathrm{deg}$ in electrical angle. Such low PPR position information may generate serious current harmonics and torque ripples as mentioned in the previous chapter. Therefore, it is necessary to acquire the rotor position with a high resolution from the low PPR encoder signals. Fortunately, a more accurate rotor speed and rotor position can be acquired by the appropriate signal processing of the rising edge and the falling edge instants of the encoder signals.

An encoder signal remaining constant at high or low levels gives no information on rotor speed or rotor position, but the rising edge and the falling edge signals may give the frequency of the rotor, that is, the rotor speed. The rotor position can be estimated in a high resolution by using the information on rotor speeds. In addition, the estimated rotor position is calibrated at every rising edge of the encoder signal.

To estimate the rotor speed from the encoder signals, we can consider two methods. One is counting the number of

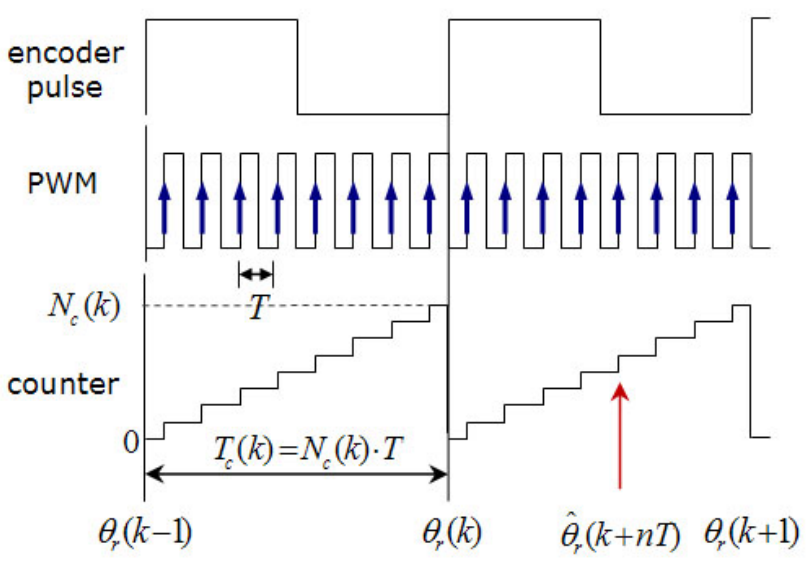

Fig. 5. Encoder pulses and estimated rotor position.

encoder pulses during a given constant period, and the other is measuring the period between the rising edges or the falling edges of the encoder pulses. Counting the number of encoder pulses is effective when the encoder has a sufficient number of encoder pulses during one revolution as is the case with a high PPR encoder. However, it is not a good candidate for a low PPR encoder because the number of encoder pulses becomes too small at low speeds. In this paper, therefore, the motor speed is estimated by measuring the period of the adjacent rising edges of the encoder signals. The period between the adjacent rising edges of the encoder signals can be measured by counting the number of high frequency counting signals, such as PWM trigger signals, whose frequency is $20 \mathrm{kHz}$. Fig. 5 shows the relationships between the encoder signal, the PWM counting signal, and the counter to estimate the rotor position.

When $N_{c}(k)$ is the number of counting pulses between the $(k-1)$ th and the $k$-th rising edges of the encoder signal, the time between the two rising edges of the encoder pulse is:

$$
T_{c}(k)=N_{c}(k) \cdot T
$$

where, $T$ is the sampling period of the PWM. If the motor speed is 60rpm, the frequency of a 64 PPR encoder signal is $64 \mathrm{~Hz}$ and the number of counting pulses $N_{c}(k)$ will be 312 , since $N_{c}(k)=20 \mathrm{kHz} / 64 \mathrm{~Hz}=312.5$. This counting number will increase at lower speeds, but it will decrease at higher speeds.

From the detected time between the two edges of the encoder signal, the mechanical frequency of the motor can be given as follows:

$$
f_{m}(k)=\frac{1}{N_{e n c}} \cdot \frac{1}{T_{c}(k)}=\frac{1}{N_{e n c} N_{c}(k) T} .
$$

The estimated electrical rotor speed $\hat{\omega}_{r}(k)$ can be derived as (15), under the assumption that the motor speed is constant during one cycle of the encoder signals,

$$
\hat{\omega}_{r}(k)=2 \pi f_{e}(k)=2 \pi \times \frac{P}{2} f_{m}(k)=\frac{P \pi}{N_{e n c} N_{c}(k) T} .
$$

From the estimated rotor speed given in (15), the rotor position between $\hat{\theta}_{r}(k)$ and $\hat{\theta}_{r}(k+1)$ can be estimated as (16). 


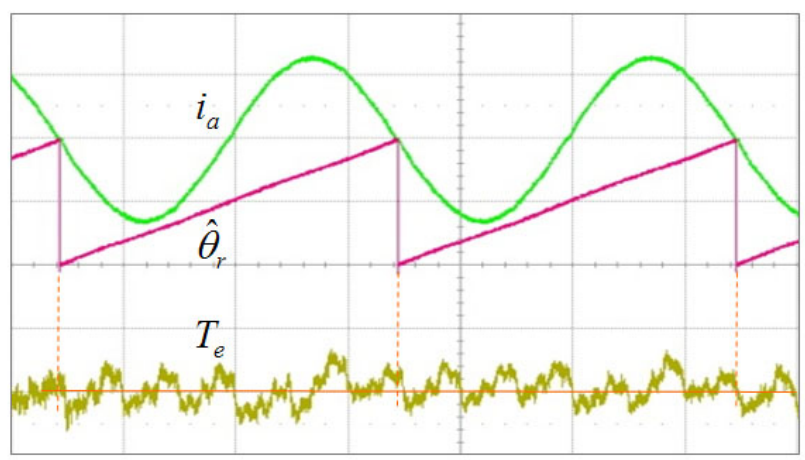

Fig. 6. Torque ripple and approximation.

$$
\widehat{\theta}_{r}(k+n T)=\theta_{r}(k)+\sum_{i=0}^{n} \hat{\omega}_{r}(k) \cdot T .
$$

It can be noted that the rotor position between the rising edges of the encoder signals can be estimated at every PWM sampling time. The estimated rotor position is also calibrated at every rising edge of the encoder signal. Furthermore, the absolute rotor position is updated every 60 electrical degrees.

\section{B. Torque ripple reduction}

The motor torque has ripples caused by the mechanical unbalance, the magnet saturation, the cogging torque, etc. Nevertheless the sinusoidal currents are applied to the stator windings. The torque ripple mainly includes multiples of the $6^{\text {th }}$ order harmonics of the fundamental frequency. As shown in Fig. 6, the torque ripple waveform includes many kinds of harmonics, therefore, it is not easy to model the torque ripples exactly. But the major component of the torque ripple is the $6^{\text {th }}$ order harmonic so that the torque ripple can be reduced by injecting an extra currents that cancel the $6^{\text {th }}$ order torque harmonic. The $6^{\text {th }}$ order torque harmonic in Fig. 6 depends on the average torque and rotor position, so it can be approximated as follows:

$$
T_{\text {har }}^{6}=-k_{6} i_{q o} \sin \left(6 \theta_{r}\right)
$$

where, $i_{q o}$ is the nominal $q$-axis current corresponding to the average torque.

The coefficient of the $6^{\text {th }}$ order torque harmonic $k_{6}$ can be decided as (18) from the measured torque ripples in Fig. 6.

$$
k_{6}=\frac{T_{\text {har_peak }}^{6}}{i_{q o}}=\frac{0.04 \mathrm{Nm}}{65 \mathrm{~A}}=0.00062 \mathrm{Nm} / \mathrm{A} .
$$

If we add the extra torque that cancels the $6^{\text {th }}$ order torque harmonic to the torque command, then the $6^{\text {th }}$ order torque harmonic will disappear. The compensating $q$-axis current corresponding to the extra torque may be expressed as:

$$
i_{q c}=-\frac{T_{h a r}^{6}}{k_{t}}=\frac{k_{6}}{k_{t}} i_{q o} \sin \left(6 \theta_{r}\right) .
$$

The reference $q$-axis current includes the nominal $q$-axis current $i_{q o}$ for average torque and the compensating $q$-axis current to reduce the torque ripple and it is given in (20).
TABLE I

SPECIFICATIONS OF PM SYNCHRONOUS MOTOR

\begin{tabular}{|l|l|}
\hline Parameters & value \\
\hline Number of Poles & 6 \\
Stator resistance @70 ${ }^{\circ} \mathrm{C}$ & $0.023 \Omega$ \\
$d$-axis inductance & $68 \mathrm{uH}$ \\
$q$-axis inductance & $68 \mathrm{uH}$ \\
Back emf constant & $0.0109 \mathrm{Vsec}$ \\
Moment of inertia & $0.00011 \mathrm{kgm}^{2}$ \\
Coefficient of viscous friction & $0.00021 \mathrm{Nmsec}$
\end{tabular}

$$
i_{q}^{*}=i_{q o}+i_{q c}
$$

\section{EXPERIMENTAL RESULTS}

Fig. 7 shows a block diagram of the proposed torque control of a PM synchronous motor for a MDPS system. The reference torque is generated from the main controller based on information such as the vehicle speed, the engine RPM, the torque sensor output, and the steering angle. The $d q$ reference currents consist of the nominal $d q$ current corresponding to the required torque and the compensating $d q$ current to reduce the torque ripple. The compensating $d q$ current depends on the torque magnitude and it has $6^{\text {th }}$ order harmonic currents to cancel the $6^{\text {th }}$ order torque ripple.

The $d q$ reference currents are compared with the $d q$ currents transformed from the $a b c$ currents based on the estimated rotor position. A proportional-integral (PI) current controller with decoupling generates the $d q$ reference voltages. Three phase voltages corresponding to the $d q$ reference voltages are applied to the motor through a space vector PWM inverter and the DC link voltage across the battery is $12 \mathrm{~V}$. The rotor speed and the rotor position are estimated by measuring the period of the low PPR encoder signals.

The torque control with rotor position estimation is implemented by a DSP, TMS320F28335. The control frequency for the current command generation and the rotor speed calculation is $420 \mathrm{~Hz}$, the current control frequency is $1.68 \mathrm{kHz}$, and the PWM frequency for the voltage control is $20 \mathrm{kHz}$. The PM synchronous motor has 3 phases and 6 poles, and the permanent magnets are mounted on the surface of the rotor core so that the $d$-axis and the $q$-axis inductances are almost equal. Fig. 8 shows the experimental system and the specifications of a PM synchronous motor are listed in Table 1.

Fig. 9(a) shows the mechanical and electrical encoder angles, the estimated rotor position, and the phase current based on the encoder signal at a constant speed of 60rpm. The reference torque is $3.2 \mathrm{Nm}$ and the $q$-axis current is $65 \mathrm{~A}$. Fig. 9(b) shows similar waveforms, except that the phase current is based on the estimated rotor position, when the motor speed accelerates from 30rpm to $85 \mathrm{rpm}$. It shows that the estimated rotor position has a high resolution at both constant and variable speeds.

Fig. 10 shows the currents and the motor torque when the motor is driven by 64PPR encoder signals without the compensating current for torque ripple reduction. The current is controlled based on the encoder signals, which have an 


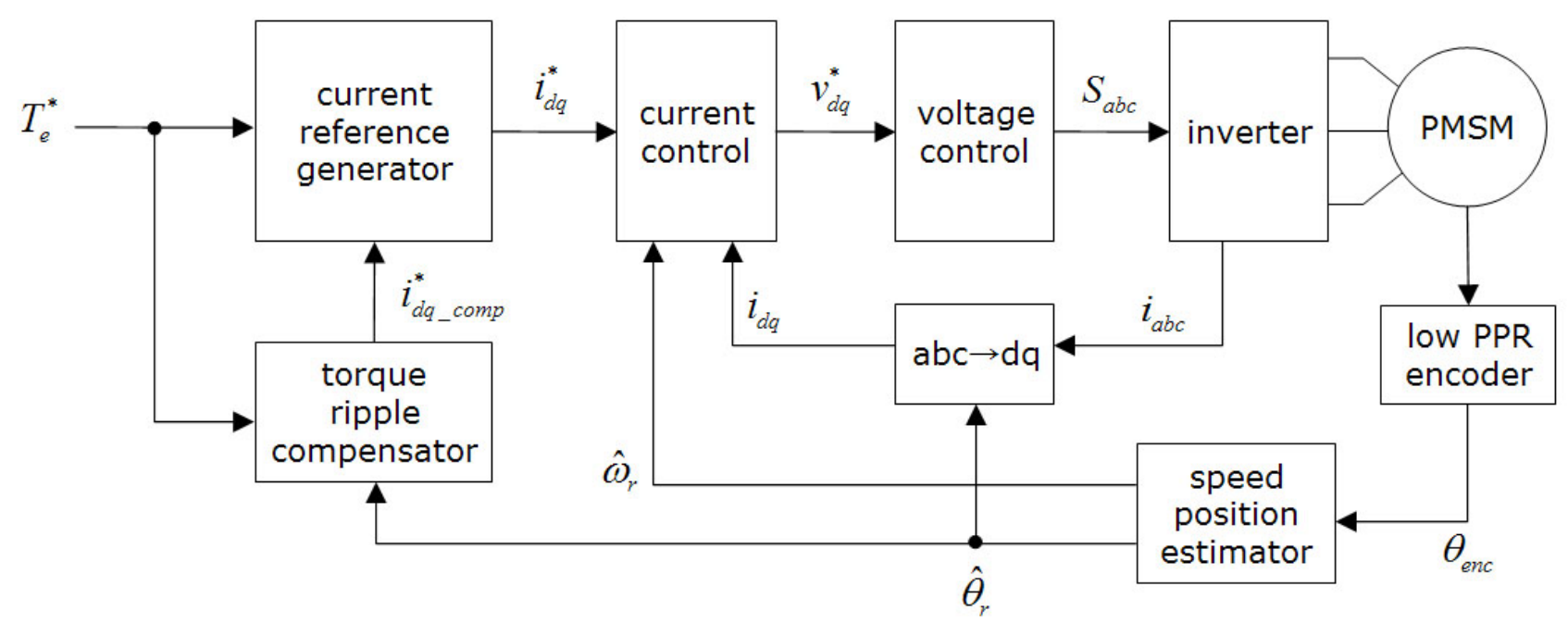

Fig. 7. Torque control schemes of PMSM

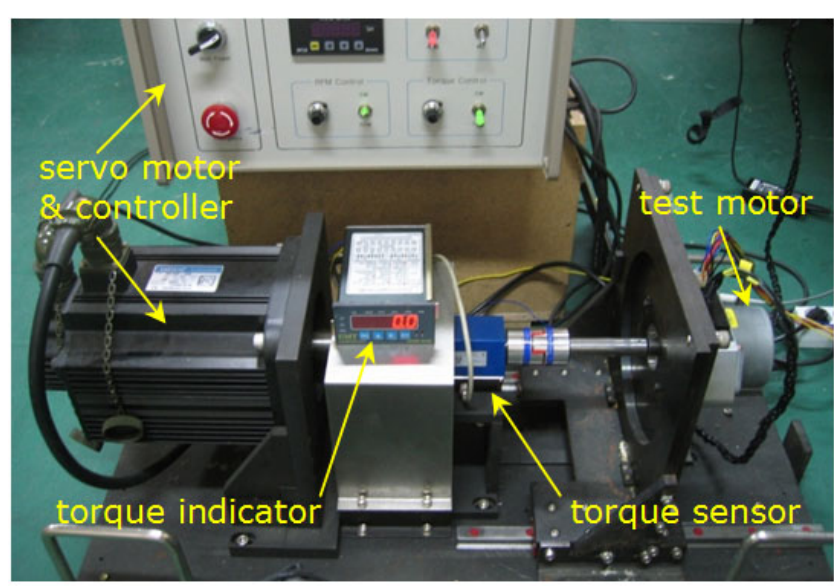

Fig. 8. Photographs of experimental system.

electrical angle resolution of 16.875 degree, so that the phase current is also quantized by the encoder signals. These quantized phase currents generate the ripples in the $d q$ currents. The motor torque, therefore, has high frequency torque ripples due to the $d q$ current ripples as well as the inherent torque ripples caused by the mechanical unbalance, the magnet saturation, and the cogging torque. The peak to peak value of the torque ripple is $0.2 \mathrm{Nm}$, which is $6.25 \%$ of the average torque. Such a large torque ripple will generate a mechanical vibration on the steering handle and it also exceeds the limits of torque ripple for MDPS systems.

Fig. 11 shows the currents and the motor torque when the motor is driven by the estimated rotor position without the compensating current. It can be noted that the $d q$ current ripples are significantly decreased and that the phase current has nearly sinusoidal waveforms since the currents are controlled by the estimated rotor position with a high resolution. The high frequency torque ripples caused by the quantized encoder signal disappears, but it still has the inherent torque harmonics caused by a combination of mechanical unbalance, magnet saturation, cogging torques, etc. The peak to peak value of the

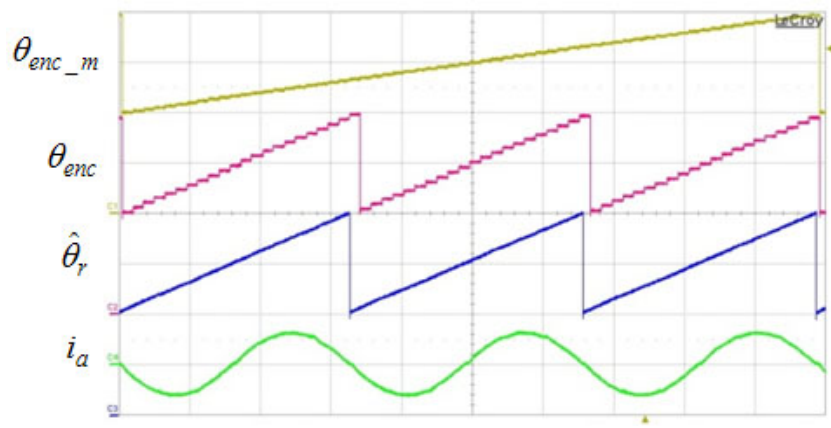

(a) Constant speed at 60rpm (time : 100msec/div.)

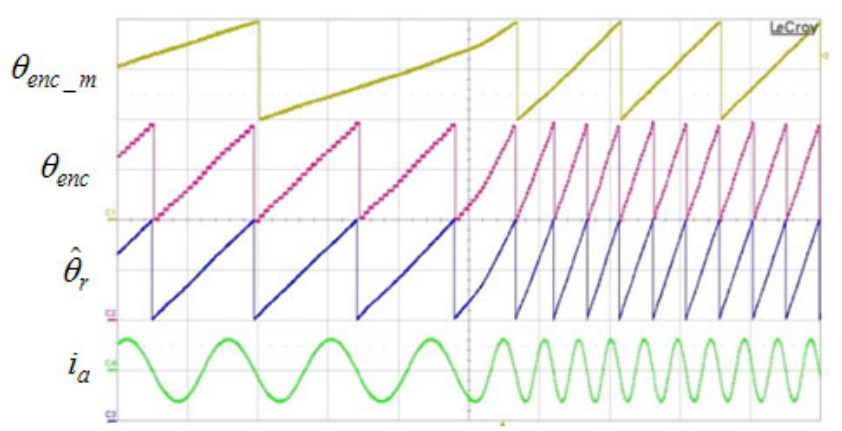

(b) Acceleration from 30rpm to $85 \mathrm{rpm}$ (time : $500 \mathrm{msec} /$ div.)

Fig. 9. Actual rotor position and estimated rotor position $\left(\theta: \pi \mathrm{rad} / \mathrm{div} ., i_{a}: 100 \mathrm{~A} / \mathrm{div}\right.$.),:

torque ripples is about $0.1 \mathrm{Nm}$, which is $3.1 \%$ of the average torque. The main component in the torque ripple is the $6^{\text {th }}$ order harmonics.

To reduce the $6^{\text {th }}$ order harmonic of the motor torque, the compensating $d q$ currents generated from the torque ripple compensator are added to the reference $d q$ currents. The $d q$ currents and the compensating $q$-axis current as well as the motor torque are shown in Fig. 12. The magnitude of the compensating $q$-axis current is $1.3 \mathrm{~A}$, about $2.0 \%$ of the nominal $q$-axis current. The compensating $q$-axis current generates the pulsating torque that cancels the inherent torque 


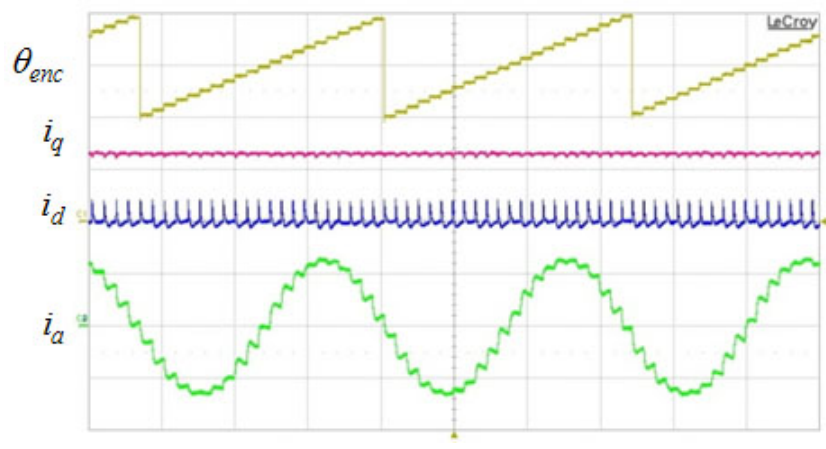

(a) Encoder angle and currents

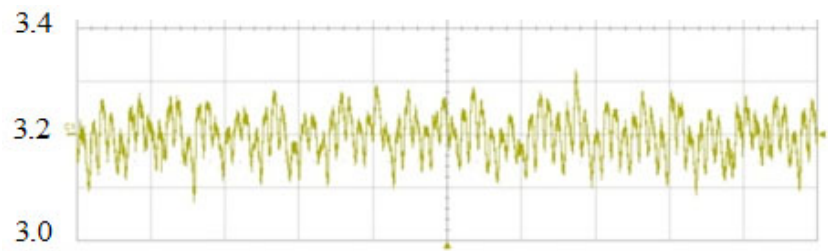

(b) Torque $(\mathrm{Nm})$

Fig. 10. Currents and torque for 64 PPR encoder without torque ripple compensation

$\left(\theta: \pi \mathrm{rad} /\right.$ div., $i_{q}, i_{d}, i_{a}: 50 \mathrm{~A} /$ div., time $: 100 \mathrm{msec} /$ div. $)$

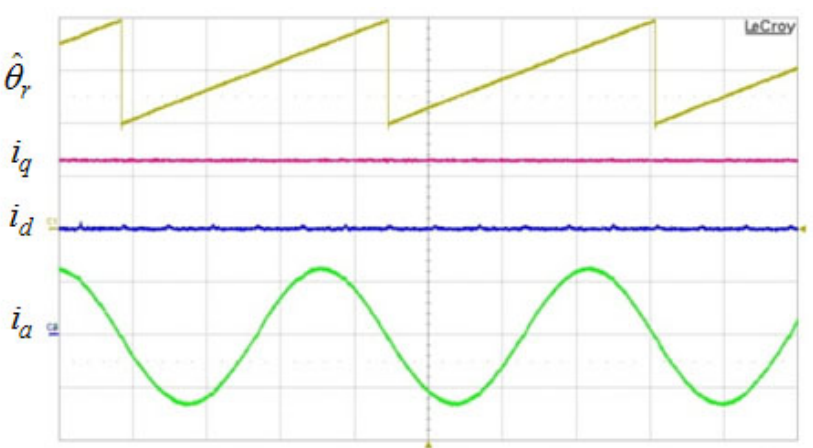

(a) Estimated rotor position and currents

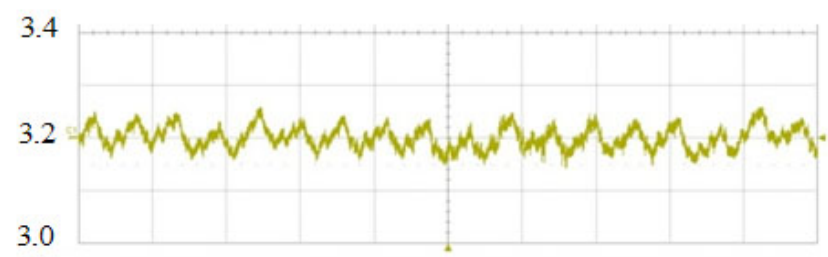

(b) Torque (Nm)

Fig. 11. Currents and torque for estimated rotor position without torque ripple compensation

$\left(\theta: \pi \mathrm{rad} /\right.$ div., $i_{q}, i_{d}, i_{a}: 50 \mathrm{~A} /$ div.,time $\left.: 100 \mathrm{~m} \mathrm{sec} / \mathrm{div}.\right)$

ripples of the motor. The peak to peak of the torque ripples is attenuated to $0.05 \mathrm{Nm}$, that is $1.6 \%$ of the average torque.

\section{CONCLUSions}

The MDPS system in a vehicle can increase the fuel efficiency and steering performance when compared to conventional hydraulic steering, but reducing the torque ripples and the material cost are important issues. In this paper, torque ripple reduction based on the estimated rotor position from a low resolution encoder is proposed. The effect of the encoder

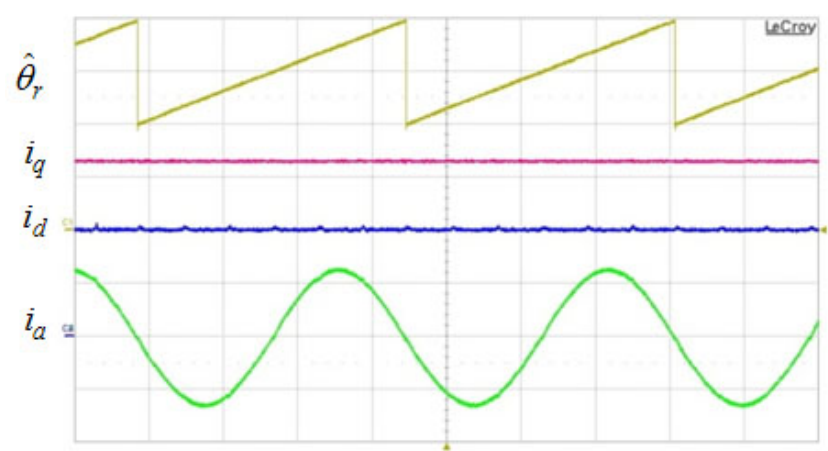

(a) Estimated rotor position and currents

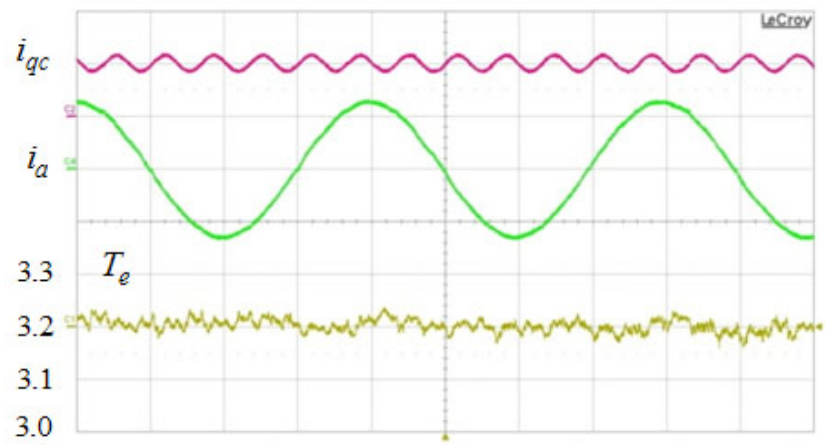

(b) Compensating current and torque $(\mathrm{Nm})$

Fig. 12. Currents and torque for estimated rotor position with torque ripple compensation

$\theta: \pi \mathrm{rad} / \mathrm{div} . i_{q}, i_{d}, i_{a}: 50 \mathrm{~A} /$ div., $i_{q c}: 5 \mathrm{~A} /$ div., time $: 100 \mathrm{msec} /$ div.

resolution on the torque ripple is analyzed. The rotor position is estimated from the low resolution encoder signals to reduce the current harmonics caused by the quantized rotor position from the low PPR encoder. To reduce the torque ripple in a MDPS system, the extra $q$-axis current that cancels the $6^{\text {th }}$ order torque harmonic is added to the reference current. By applying the estimated rotor position and the torque ripple compensation, the peak to peak torque ripple is reduced from $6.25 \%$ to $1.6 \%$. The performance of the proposed torque ripple reduction based on an estimated rotor position is verified through experimental results.

\section{ACKNOWLEDGMENT}

This research was supported by Hyundai-Mobis and the MKE (The Ministry of Knowledge Economy), Korea, under an ITRC (Information Technology Research Center) support program supervised by the NIPA (National IT Industry Promotion Agency" (NIPA-2009- (C1090-0904-0007)).

\section{REFERENCES}

[1] A. W. Burton, "Innovation drivers for electric power-assisted steering," IEEE Control Systems Magazine, pp. 30-39, Nov. 2003.

[2] H. Eki, T. Teratani, and T. Iwasaki, "Power consumption and conversion of EPS systems," in Power Conversion Conference (PCC), pp. 13331339, 2007.

[3] G. Ombach and J. Junak, "Two rotors designs' comparison of permanent magnet brushless synchronous motor for an electric power steering application," in European Conference on Power Electronics and Applications(EPE), pp. 1-9, 2007.

[4] N. Bianchi, Michele D. Pre, and S. Bolognani, "Design of a fault-tolerant IPM motor for electric power steering," IEEE Trans. on Vehicular Technology, Vol. 55, No. 4. pp. 1102-1111, Jul. 2006. 
[5] L. Xinhua, W. Jie, Z. Zhiwei, and Z. Baixing, "Development of EPS rare-earth permanent-magnet brushless direct current motor," in proceedings of International Conference on Electrical Machines and Systems(ICEMS), Vol. 3, pp. 2302 - 2305, 2005

[6] J. Ahn, S. B. Lim, K. C. Kim, J. Lee, J. H. Choi, S. Kim, and J. P. Hong, "Field weakening control of synchronous reluctance motor for electric power steering," IET Electrical Power Applications, Vol. 1, No. 4, pp. 565-570, Jul. 2007.

[7] Y. H. Cho, Y. W. Jeong, and S. C. Yun, "Development of motor driven power steering control system using surface mounted permanent magnet synchronous motor, " in Conf. of KIPE, pp. 85-87, Nov. 2006.

[8] C. J. Yoo, "An Experimental study on motor noise reduction of electric power steering," Journal of the Korea Society for Power System Engineering, Vol. 12, No. 6, pp. 83-87, Dec. 2008.

[9] S. Chen, "Controller-induced parasitic torque ripples in a PM synchronous motor," IEEE Transactions on Industry Applications, Vol. 38, No. 5, pp. 1273-1281, Sep./Oct. 2002.

[10] G. L. Kurnia, A. D. Larminat, R. Desmond, and P. O'Gorman, "A low torque ripple PMSM drive for EPS applications," IEEE Applied Power Electronics Conference and Exposition (APEC), Vol. 2, pp. 1130-1136, 2004.

[11] J. Wu and Y. Y. Wang, "A new technique for reducing cogging torque in EPS permanent magnet brushless DC motor," in International Conference on Electrical Machines and Systems(ICEMS), pp. 789-791, 2007.

[12] L. Gasparin and R. Fiser, "Intensity of the native and additional harmonic components in cogging torque due to design parameters of permanentmagnet motors," in International Conference on Power Electronics and Drive Systems, pp. 1062 - 1067, 2009.

[13] G. H. Lee, "Active cancellation of PMSM torque ripple caused by magnetic saturation for EPS applications," Journal of Power Electronics, Vol. 10, No. 2, pp. 176-180, Mar. 2010.

[14] G. Liu, A. Kurnia, R. D. Larminat, and S. J. Rotter, "Position sensor error analysis for EPS motor drive," in International Electric Machines and Drives Conference(IEMDC), Vol. 1, pp. 249 - 254, 2003.

[15] H. S. Mok, J. M. Lee, G. H. Choe, S. H. Kim, and Y. H. Cho, "Analysis and a compensation method for torque ripple caused by position sensor error in PMSM's vector control," Journal of the Korean Institute of Power Electronics, Vol. 12, No. 6, pp. 449-455, Dec. 2007.

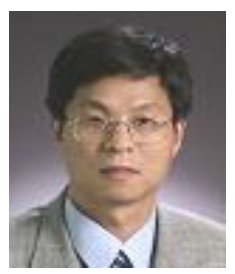

Kwan-Yuhl Cho received his B.S. in Electrical Engineering from Seoul National University, Seoul, Korea, in 1986, and his M.S. and Ph.D. in Electrical and Electronic Engineering from the Korea Institute of Science and Technology (KAIST), Daejon, Korea, in 1988 and 1993, respectively. He worked for LG Electronics, Digital Appliance Research Lab., from 1993 to 2004. Since 2004, he has been with the Department of Control and Instrumentation Engineering at Chungju National University, Korea. His research interests are in the areas of variable speed motor drives and power converters. $\mathrm{He}$ is a member of the Korean Institute of Power Electronics (KIPE) and a publication editor of the Journal of Power Electronics (JPE).

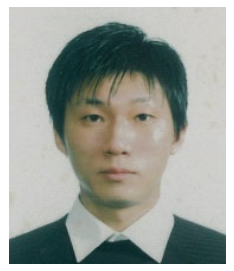

Yong-Kyun Lee was born in Seoul, Korea in 1977. He received his B.S. and M.S. in Electrical Engineering from Konkuk University, Seoul, Korea in 2001 and 2005 , respectively. He is currently working toward his Ph.D. at Konkuk University. Since 2005, He has been a Research Engineer with Vctech. His current research interests include ac machine drives for electric vehicles.

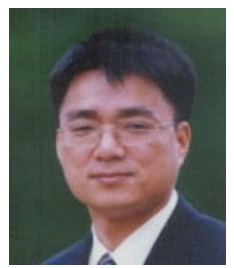

Hyungsoo Mok received the B.S., M.S. and Ph.D. degrees in electrical engineering from Seoul National University, Korea, in 1986, 1988, and 1992, respectively. He was with the Department of Control and Instrumentation Engineering at Seoul National Polytechnic University from 1993 to 1997. Since 1997, he has been with the Department of Electrical Engineering at Konkuk University. His teaching and research interests include electric machines, electric machine drive systems, and power electronic control for industrial and power systems.

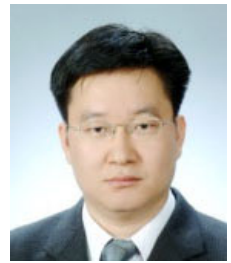

Hag-Wone Kim received his B.S. in Electrical Engineering from Korea University, Seoul, Korea, in 1989 , and his M.S. and Ph.D. in Electrical and Electronic Engineering from the Korea Institute of Science and Technology (KAIST), Daejon, Korea, in 1991 and 2004, respectively. He worked for LG Electronics, Digital Appliance Research Lab., from 1991 to 2008. Since 2008, he has been with the Department of Control and Instrumentation Engineering at Chungju National University, Korea. His research interests are in the areas of variable speed motor drives and power converters. He is a member of the Korean Institute of Power Electronics (KIPE) and the Institute of Electrical and Electronics Engineers (IEEE).

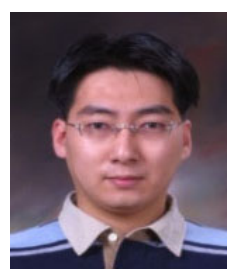

Byoung-Ho Jun received his B.S. and M.S. in Electrical Engineering from Inha University, Incheon, Korea, in 2001 and 2004 respectively. Since 2004, he has been working for Hyundai-Mobis, Chassis Electronic Engineering Team. His current research interest is in the area of electronic control units (ECU) for vehicles using PMSM. He is a member of the Korean Institute of Power Electronics (KIPE).

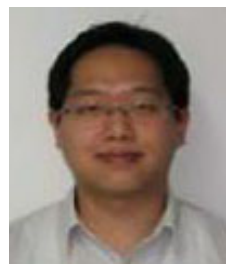

Younghoon Cho received his M.S. in Electrical and Computer Engineering from Seoul National University, Seoul, Korea, in 2004. From 2004 to 2009, he worked as an engineer in the Technical Research Institute at Hyundai MOBIS. He is currently pursuing his Ph.D. at Virginia Tech, Blacksburg, USA. His research interest includes multi-phase, multi-level high power converters, machine drives and high performance DSP applications for $\mathrm{EV}, \mathrm{HEV}$ and renewable energy applications. 